\title{
Electrical stimulation and electromagnetic field use in patients with diabetic neuropathy: systematic review and meta-analysis
}

\author{
Cinara Stein ${ }^{1}$, Bruna Eibel $^{2}$, Graciele Sbruzzi ${ }^{2,3}$, Pedro D. Lago ${ }^{1}$, \\ Rodrigo D. M. Plentz ${ }^{1,2}$
}

\begin{abstract}
Background: Painful diabetic neuropathy (PDN) is a common complication of diabetes mellitus, and pharmacological therapies are ineffective in many patients. Therefore, other treatment modalities should be considered, including electrical stimulation and electromagnetic fields. Objectives: The research objective was to evaluate the effect of treatment with electrical stimulation and electromagnetic fields on pain and sensitivity in patients with painful diabetic neuropathy compared with placebo or another intervention. Method: We searched the following electronic databases (from inception to April 2012): MEDLINE (accessed by PubMed), LILACS, Physiotherapy Evidence Database (PEDro), EMBASE and Cochrane CENTRAL. We included randomized trials that compared electrical stimulation or electromagnetic fields with control groups in which the objective was to assess pain and sensitivity in patients with PDN. Two reviewers independently extracted the data. A random-effects model was used for the main analysis. Results: The search retrieved 1336 articles, of which 12 studies were included. Reductions in the mean pain score were significantly greater in the TENS (transcutaneous electrical nerve stimulation) group than in the placebo group [ -0.44 (95\% CI: -0.79 to $-0.09 ; \mathrm{I} 2: 0 \%)$ ]. There was no improvement in pain relief when electromagnetic fields were compared with the control group [-0.69 (95\% CI: -1.86 to 0.48; I2: 63\%)]. Conclusions: We found that TENS improved pain relief in patients with diabetic neuropathy, while no such improvement was observed with the use of electromagnetic field treatment. Due to the methodological differences between the studies, a meta-analysis for the outcome of sensitivity could not be performed.
\end{abstract}

Keywords: physical therapy; diabetic neuropathies; electrical stimulation; electromagnetic fields; pain; review.

\section{HOW TO CITE THIS ARTICLE}

Stein C, Eibel B, Sbruzzi G, Lago PD, Plentz RDM. Electrical stimulation and electromagnetic field use in patients with diabetic neuropathy: systematic review and meta-analysis. Braz J Phys Ther. 2013 Mar-Apr; 17(2):93-104. http://dx.doi.org/10.1590/ S1413-35552012005000083

\section{Introduction}

Diabetes mellitus (DM) is a common chronic disease with a predicted prevalence of 366 million patients by $2030^{1}$. Peripheral neuropathy is one of the most serious complications of both type 1 and type $2 \mathrm{DM}^{2}$, with a prevalence to up $50 \%$ of $\mathrm{DM}$ cases $^{3}$. One of the most distressing symptoms that people can suffer from is neuropathic pain and paresthesia ${ }^{4}$. Painful diabetic neuropathy (PDN) can cause symptoms that last for years and severely impair quality of life ${ }^{5}$, and the PDN prevalence is $26.4 \%$ in $\mathrm{DM}^{6}$.

The etiology of diabetic neuropathy is not well understood because it is based on the clinical symptoms of individuals. The treatment options are limited, which may explain why up to $50 \%$ of patients have not requested or received treatment for the condition ${ }^{7}$. Analgesics, antidepressants and anticonvulsants are often prescribed, with varied responses ${ }^{8}$. As several studies have suggested, nonpharmacological options, such as electrical stimulation, which represents one of the more benign therapies for this condition ${ }^{9}$, may contribute to a better quality of life and fewer complaints of pain ${ }^{10}$.

In randomized trials, various types of electrotherapy, such as transcutaneous electric nerve stimulation (TENS) $)^{11-15}$, pulsed electromagnetic fields ${ }^{16-19}$, static magnetic field therapy ${ }^{20}$, low-frequency pulsed magnetic field ${ }^{21}$, high-frequency external muscle stimulation $(\mathrm{HF})^{22}$, frequency-modulated electromagnetic neural stimulation (FREMS) ${ }^{23}$ and percutaneous electrical nerve stimulation (PENS) ${ }^{24}$, have been reported to show beneficial effects, such as decreased pain and improved sensitivity, due to

\footnotetext{
${ }^{1}$ Physical Therapy Department, Universidade Federal de Ciências da Saúde de Porto Alegre (UFCSPA), Porto Alegre, RS, Brazil

${ }^{2}$ Laboratory of Clinical Investigation, Instituto de Cardiologia do Rio Grande do Sul/Fundação Universitária de Cardiologia (IC/FUC),

Porto Alegre, RS, Brazil

${ }^{3}$ Physical Therapy Department, Universidade Federal do Rio Grande do Sul (UFRGS), Porto Alegre, RS, Brazil

Received: 10/14/2012 Revised: 10/23/2012 Accepted: 10/29/2012
} 
electric stimulation in the treatment of patients with PDN.

Previous randomized trials showed the beneficial effects of electrical stimulation in the treatment of patients with PDN compared with placebo. However, studies comparing these benefits with those obtained from placebo had small sample sizes and showed conflicting results ${ }^{11-15,18-24}$. A systematic review of the evidence would allow for a more precise evaluation of its effectiveness and, if the benefits are proven, aid in disseminating the use of electrical stimulation. Therefore, the aim of our study was to systematically review the effect of treatment with electrical stimulation and electromagnetic field use on pain and sensitivity in patients with PDN compared with placebo or another intervention.

\section{Method}

This systematic review was performed in accordance with the Cochrane Collaboration and statements for systematic review ${ }^{25}$ and Preferred Reporting Items for Systematic Review and Metaanalyses: The PRISMA Statement ${ }^{26}$.

\section{Search strategy}

We searched the following electronic databases (from inception to April 2012): MEDLINE (accessed by PubMed), LILACS, Physiotherapy Evidence Database (PEDro), EMBASE and Cochrane Central Register of Controlled Trials (Cochrane CENTRAL). The search terms used included 'diabetic neuropathies', 'diabetic polyneuropathy', 'diabetic asymmetric polyneuropathy', 'TENS', 'transcutaneous electrical nerve stimulation', 'transcutaneous electrical stimulation', 'electric stimulation', 'electrical stimulation', 'electromagnetic fields', 'electromagnetic field', 'field, electromagnetic' and a string of words previously proposed ${ }^{27}$, which yielded a high sensitivity in the search for randomized controlled trials (RCTs). To enhance the sensitivity of our search, we did not include words related to the outcomes of interest. There were no language restrictions.

The references included in the published articles identified in these searches were used as an additional source to identify other clinical trials. The complete search strategy used for the PubMed database is shown in Table 1.

Table 1. Literature search strategy used for the PubMed database.

\#1 Diabetic Neuropathies OR Diabetic Neuropathy OR Neuropath\$, Diabetic OR Diabetic Polyneuropath\$ OR Polyneuropath\$, Diabetic OR Asymmetric Diabetic Proximal Motor Neuropathy OR Diabetic Asymmetric Polyneuropathy OR Asymmetric Polyneuropath\$, Diabetic OR Diabetic Asymmetric Polyneuropathies OR Polyneuropath\$, Diabetic Asymmetric OR Diabetic Autonomic Neuropathy OR Autonomic Neuropath\$, Diabetic OR Diabetic Autonomic Neuropathies OR Neuropath\$, Diabetic Autonomic OR Symmetric Diabetic Proximal Motor Neuropathy OR Diabetic Amyotrophy OR Amyotroph\$, Diabetic OR Diabetic Amyotrophies OR Diabetic Neuralgia OR Diabetic Neuralgias OR Neuralgias, Diabetic OR Diabetic Neuropath\$, Painful OR Neuropath\$, Painful Diabetic OR Painful Diabetic Neuropath\$ OR Neuralgia, Diabetic OR Diabetic Mononeuropath\$ OR Mononeuropath\$, Diabetic OR Diabetic Mononeuropathy Simpl\$ OR Mononeuropathy Simpl\$, Diabetic OR Simpl\$, Diabetic Mononeuropathy OR Diabetes Complication\$ OR Diabetes Complication OR Diabetes-Related Complication\$ OR Diabetes Related Complications OR Diabetic Complication\$ OR Complications of Diabetes Mellitus OR Diabetes Mellitus Complication\$

\#2 Electric\$ Stimulation OR Electrical Stimulations OR Stimulation\$, Electrical OR Stimulation\$, Electric OR Electric Stimulations OR Electric Stimulation Therapy OR Therapeutic Electric Stimulation OR Electric Stimulation, Therapeutic OR Stimulation, Therapeutic Electric OR Therapy, Electric Stimulation OR Stimulation Therapy, Electric OR Electrotherapy OR Transcutaneous Electric \$ Nerve Stimulation OR Electrical Stimulation, Transcutaneous OR Stimulation, Transcutaneous Electrical OR Transcutaneous Electrical Stimulation OR Percutaneous Electric\$ Nerve Stimulation OR Transdermal Electrostimulation OR Electrostimulation, Transdermal OR Transcutaneous Nerve Stimulation OR Nerve Stimulation, Transcutaneous OR Stimulation, Transcutaneous Nerve OR Electric Stimulation, Transcutaneous OR Stimulation, Transcutaneous Electric OR Transcutaneous Electric Stimulation OR TENS OR Electroanalgesia OR Analgesic Cutaneous Electrostimulation OR Cutaneous Electrostimulation, Analgesic OR Electrostimulation, Analgesic Cutaneous OR Electromagnetic Fields OR Electromagnetic Field OR Field, Electromagnetic OR Fields, Electromagnetic

\#3 Randomized controlled trial[pt] OR controlled clinical trial[pt] OR randomized controlled trials[mh] OR random allocation[mh] OR double-blind method[mh] OR single-blind method[mh] OR clinical trial[pt] OR clinical trials[mh] OR (“clinical trial”" $[\mathrm{tw}])$ OR ((singl*[tw] OR doubl*[tw] OR trebl*[tw] OR tripl*[tw]) AND (mask*[tw] OR blind*[tw])) OR ("latin square"[tw]) OR placebos[mh] OR placebo*[tw] OR random*[tw] OR research design[mh:noexp] OR follow-up studies[mh] OR prospective studies[mh] OR cross-over studies[mh] OR control*[tw] OR prospectiv*[tw] OR volunteer*[tw]

\#4 \#1 AND \#2 AND \#3 


\section{Eligibility criteria}

We included RCTs that evaluated electrical stimulation (TENS, HF, FREMS, or PENS) or electromagnetic fields in the treatment of PDN. We included studies that compared electrical stimulation or electromagnetic fields with placebo in which the objective was to assess pain and sensitivity. In all studies, the placebo consisted of no electric current transmission or no exposure to magnetic fields. We only included studies that applied electrical stimulation to the lower and upper extremities. The exclusion criteria were the following: (1) the inclusion of subjects other than PDN patients; (2) an unreliable description of what was considered PDN; and (3) lack of control group data description.

\section{Study selection and data extraction}

The titles and abstracts of all articles identified using the search strategy were evaluated by two investigators (C.S. and B.E.) in duplicate. All abstracts that did not provide enough information regarding the inclusion and exclusion criteria were selected for full-text evaluation. In the second phase, the same reviewers independently evaluated the fulltext articles and made their selection in accordance with the eligibility criteria. Disagreements between the reviewers were solved by consensus. The main outcome extracted was pain relief. Other outcomes of interest were sensitivity and the length of treatment.

\section{Assessment of risk of bias}

The major quality issues assessed were the following: adequate sequence generation, allocation concealment, blinding, blinding assessors, description of losses and exclusions and intention-to-treat analysis. Studies without a clear description of the use of intention-to-treat analysis were considered not to have fulfilled this criterion.

The lack of a description of how the allocation list was concealed was judged as an absence of allocation concealment. The only possible blinding in this type of study was outcomes assessment. Studies in which there was no description of this type of blinding were judged to be open. This appraisal was independently performed by two reviewers.

\section{Data analysis}

Pooled-effect estimates were obtained by comparing the least square mean percentage change from baseline to study end for each group. Regarding continuous outcomes, if the unit of measurement was consistent across trials, the results were presented as the weighted mean difference with $95 \%$ confidence intervals (CIs), and if the unit of measurement was inconsistent, the results were expressed as the standard mean difference with $95 \% \mathrm{CIs}^{25}$. Calculations were performed using a random-effects method. An $\alpha$ value $\leq 0.05$ was considered statistically significant. The statistical heterogeneity of the treatment effects among studies was assessed using Cochran's Q test and the inconsistency $\mathrm{I}^{2}$ test, in which values above $25 \%$ and $50 \%$ were considered indicative of moderate and high heterogeneity, respectively ${ }^{28}$. All analyses were conducted using Review Manager, version 5.0. A sensitivity analysis was carried out considering the statistical heterogeneity and the duration of the intervention studies.

\section{Results}

\section{Description of studies}

The search strategy yielded 1336 abstracts, of which 14 studies were considered as potentially relevant and retrieved for detailed analysis. However, only 12 studies with a total of 817 patients with PDN met the eligibility criteria for the systematic review. Figure 1 shows the flow diagram of the studies included in this review, and Table 2 summarizes the characteristics of these studies.

Five trials ${ }^{11-15}$ compared TENS to placebo (total $\mathrm{n}=132$, of which 75 were on TENS), one trial 22 compared TENS to HF (total $n=41$, of which 21 were on TENS), one trial ${ }^{23}$ compared FREMS to placebo (total $n=62$, of which 31 were on FREMS), one trial ${ }^{24}$ compared PENS to placebo (total $n=50$, of which 25 were on PENS), and four trials ${ }^{18-21}$ compared electromagnetic field to placebo (total $n=532$, of which 268 were on electromagnetic field).

\section{Risk of bias}

The included studies showed $58 \%$ adequate sequence generation and $0 \%$ allocation concealment, and $50 \%$ were blinded, $33 \%$ had blinded assessors, $50 \%$ presented a description of loss and exclusions, $17 \%$ had an intention-to-treat analysis, and $83 \%$ had no intention-to-treat analysis.

\section{Effects of interventions}

\section{Pain}

Of the included articles, five studies used TENS versus placebo, four used electromagnetic field versus placebo, one study compared TENS versus HF, one 


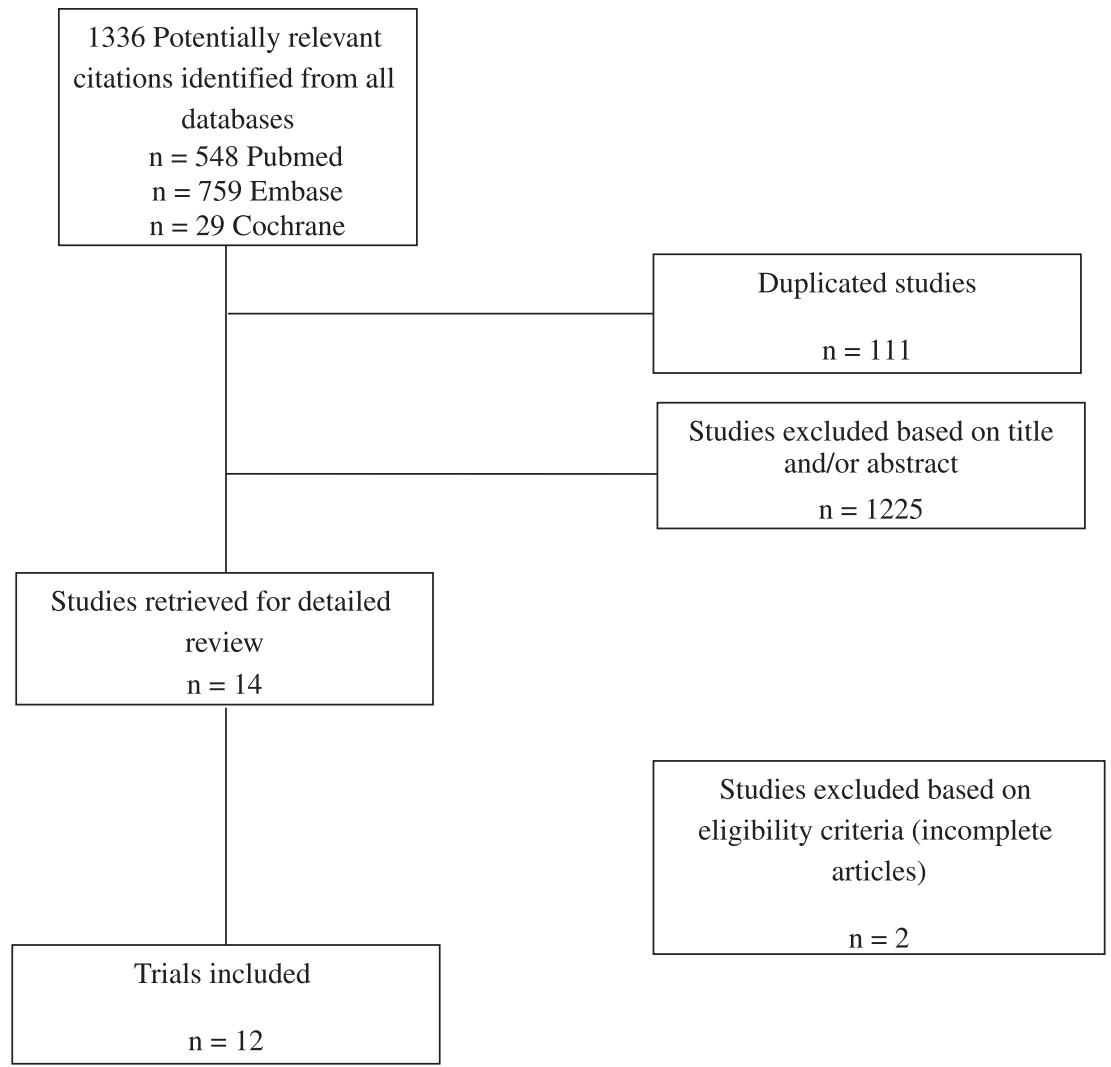

Figure 1. The flow diagram of studies included in the review.

study compared FREMS versus placebo, and two studies compared PENS versus placebo.

\section{Transcutaneous electric nerve stimulation versus placebo}

There was pain improvement in the articles that compared TENS versus placebo ${ }^{11-15}[-0.44(95 \% \mathrm{CI}$ : -0.79 to -0.09 ; I2: $0 \%, \mathrm{p}=0.01$ )] (Figure $2 \mathrm{~A}$ ).

\section{Treatment duration}

In a sub-analysis of studies on TENS in patients with PND at different treatment durations, four studies ${ }^{11,13-15}$ involved treatment for two, four and six weeks, which resulted in improvement in pain relief compared to placebo [ -0.54 (95\% CI: -1.02 to -0.06 ; I2: $26 \%, \mathrm{p}=0.03$ )] (Figure 2A).

Two other studies ${ }^{12,13}$ involved 12 weeks of treatment with TENS compared to placebo and showed no significant reduction in pain $[-0.47$ (95\% CI: -1.10 to 0.16 ; I2: 0\%, p=0.14) ] (Figure 2A).

\section{Electromagnetic field versus placebo}

Of the articles comparing electromagnetic field use versus placebo group, one showed no significant improvement in pain relief $[-0.69$ (95\% CI: -1.86 to $0.48 ;$ I2: 63\%, $\mathrm{p}=0.25)]$ (Figure 2B) $)^{18-21}$.

\section{Transcutaneous electric nerve stimulation versus $\mathrm{HF}$}

A meta-analysis could not be performed, as there was only one included study that compared TENS versus HF. This study ${ }^{22}$ showed that HF was more effective than TENS in relieving pain in patients with PDN (80\% versus $33 \%$, $\mathrm{p}<0.05)$.

\section{Frequency-modulated electromagnetic neural stimulation versus placebo}

The study ${ }^{23}$ demonstrated a decrease in pain before and after treatment with FREMS in the day-time pain score $(37.1 \pm 5.3$ to $26.2 \pm 3.9, \mathrm{p}=0.0025)$ and nighttime pain score $(38.1 \pm 5.5$ to $28.5 \pm 3.8, \mathrm{p}=0.0107)$ compared with placebo [ $(31.2 \pm 3.9$ to $31.9 \pm 4.2, \mathrm{NS})$ and (33.3 \pm 3.8 to $30.4 \pm 4.2$, NS), respectively].

\section{Percutaneous electrical nerve stimulation versus placebo}

The study ${ }^{24}$ showed a reduction in pain when the periods before and after treatment with PENS 


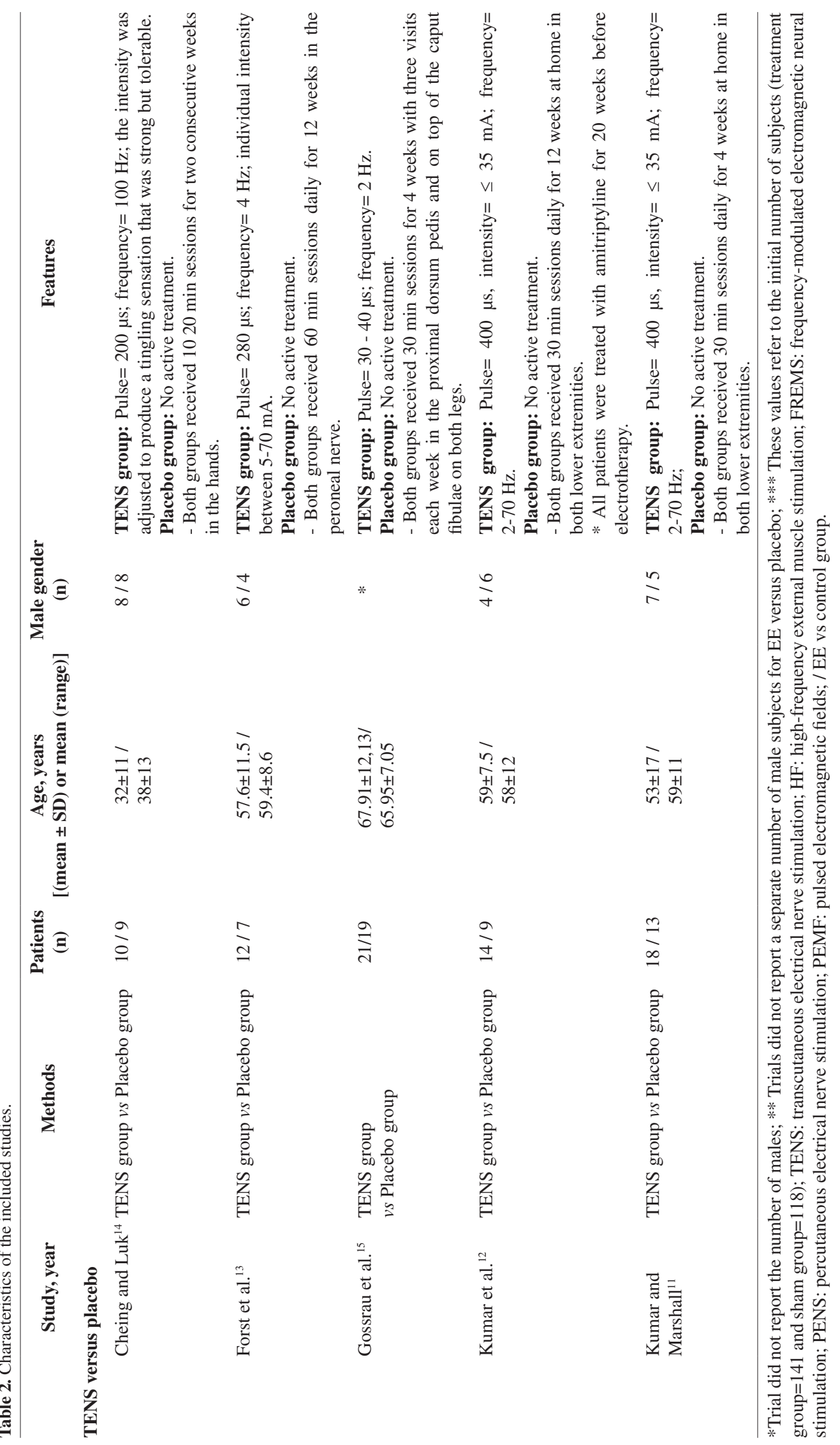




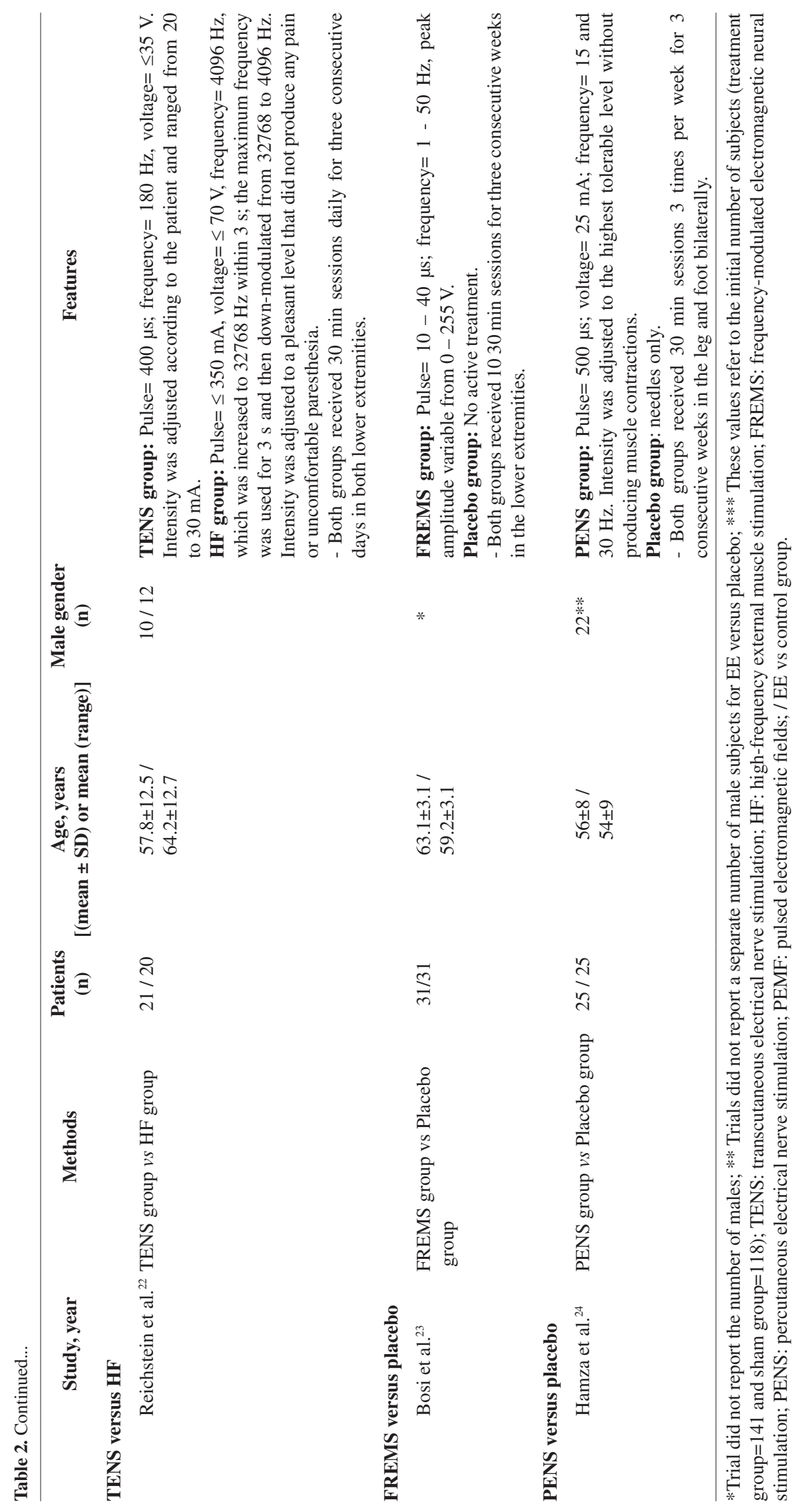




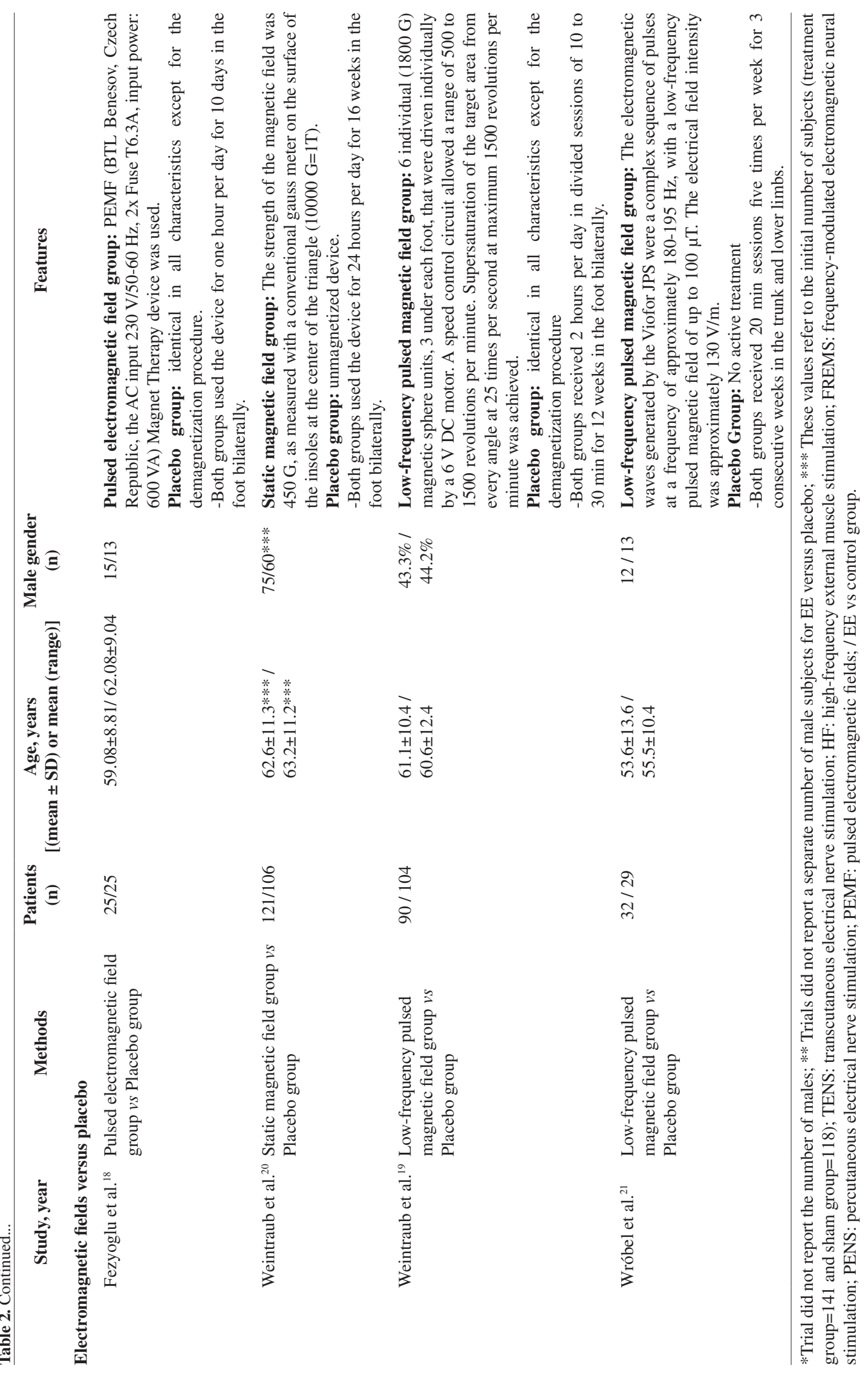


(A)

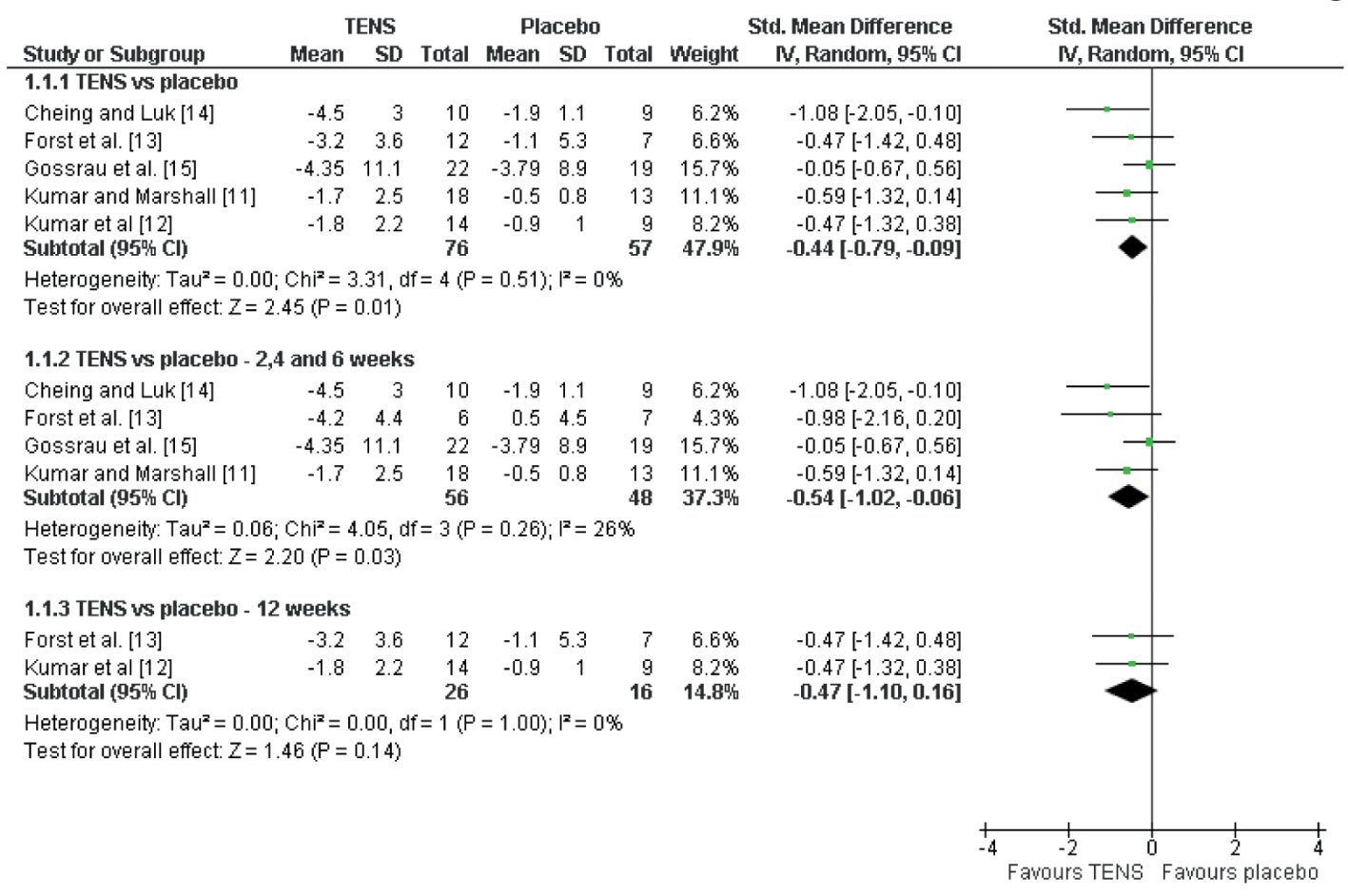

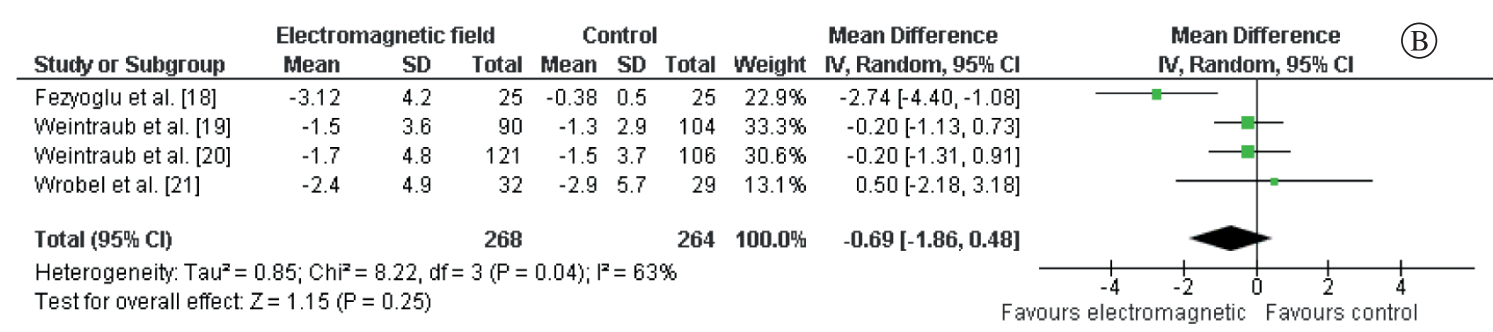

Figure 2. A) The mean weighted difference and $95 \%$ confidence interval (CI) in pain for treatment with transcutaneous electrical nerve stimulation (TENS) versus placebo. B) The mean weighted difference and 95\% CI in pain for treatment with the electromagnetic field versus control.

were compared $(6.2 \pm 1.0$ to $2.5 \pm 0.8, \mathrm{p}<0.05)$. This reduction did not occur in the placebo group $(6.4 \pm 0.9$ to $6.3 \pm 1.1, \mathrm{NS}$ ).

\section{Sensitivity}

Of the included articles, two studies used TENS versus placebo, and another study compared FREMS versus placebo.

\section{Transcutaneous electric nerve stimulation versus placebo}

Two studies assessed sensitivity in patients with diabetic neuropathy. One study ${ }^{14}$ evaluated sensitivity using 10 different textures and showed an improvement in sensitivity compared with the placebo group on the 7 th day $(8.0 \pm 2.6$ versus $5.5 \pm 1.8$, $\mathrm{p}=0.005)$ and 11 th day $(9.3 \pm 3.0$ versus $6.6 \pm 1.9$, $\mathrm{p}=0.006$ ) of treatment with TENS.

The other study ${ }^{13}$ evaluated the effectiveness of TENS at the threshold of sensory nerves in the lower limb compared to the control group. Although there were no significant changes in either group, there was a tendency toward an improvement in the sensitivity to heat and cold and the heat pain perception threshold in the TENS group.

\section{Frequency-modulated electromagnetic neural stimulation versus placebo}

The study ${ }^{23}$ evaluated changes in sensitivity to monofilament and vibration perception thresholds 
before and after FREMS. The authors observed a decrease in the number of points that were insensitive to the Semmes-Weinstein monofilament $(5.8 \pm 0.8$ to $4.6 \pm 0.9, \mathrm{p}<0.0077)$ and a decrease in the vibration perception threshold ( $35.5 \pm 1.6$ to $33.4 \pm 1.6$, $\mathrm{p}<0.0001)$. None of the outcome measures changed significantly during treatment with placebo.

\section{- Discussion}

\section{Summary of evidence}

We conducted this study to evaluate the evidence available on the effectiveness of electrical stimulation and electromagnetic stimulation in patients with diabetic neuropathy. The results show that electrical stimulation applied using TENS was an adjunct treatment option that provides an improvement in pain relief in patients with PND. However, electromagnetic stimulation showed no effect on pain relief.

The use of electrical stimulation in patients with diabetic neuropathy has been proposed as an alternative non-pharmacological treatment ${ }^{9}$. The effects of TENS may be explained by the production of endogenous opioids and gate control mechanisms. Several studies have demonstrated that low-frequency TENS increases the release of endogenous opioids, which have modulatory effects on the nucleus of the solitary tract (NTS) and, consequently, on the central nervous pathway of cardiovascular control ${ }^{29,30}$.

In contrast, some authors report that highfrequency TENS acts by stimulating large-diameter afferent fibers, inhibiting second-order neurons in the dorsal horn and preventing impulses carried by small-diameter fibers from being transmitted ${ }^{31}$. This theory proposes that unmyelinated $\mathrm{C}$ fibers and thinly myelinated A- $\delta$ fibers transmit information to the spinal cord, resulting in reflex sympathetic vasoconstrictor stimulation. Its effects are associated with one primary mechanism in which this electrical current produces pain relief, the "gate control theory" 32 . More recent literature has shown that both low- and high-frequency TENS reduces pain through the activation of opioids receptors. Low-frequency TENS activates mu opioid receptors, and highfrequency TENS activates delta opioid receptors ${ }^{33}$.

However, the effects of electromagnetic stimulation result from interruptions in the direct or indirect activation of afferent signals from fiber type $\mathrm{C}$ to the distal part of the axon, which produces an antinociceptive effect ${ }^{20}$.
Our study also showed that TENS treatment provided an improvement in pain relief at different times of treatment and a decrease in the hypersensitivity of the hands of patients compared to placebo ${ }^{14}$ and improvement in the threshold of sensory nerves of the lower limbs compared to placebo $^{13}$. Additionally, we observed that FREMS induced an increase in sensory tactile perception, as assessed with a monofilament, and a decrease in the foot vibration perception threshold. The pain in these patients most likely occurs due to central sensitization of spinal nociceptive neurons induced by ectopic activity in injured fibers ${ }^{34}$. The ongoing peripheral neural activities may enhance the release of neurotransmitters in the spinal cord, which may cause hyperexcitable responses to subsequently evoked stimuli $^{34}$. Most likely due to the above-mentioned action mechanisms, chronically applied TENS acts throughout this process by reducing the symptoms related to pain.

\section{Strengths and limitations of the review}

The studies included in this review are of limited methodological quality and show some biases that weaken the power of the information. Eight studies properly described the generation of a random sequence $\mathrm{e}^{13,14,18,19,20,22,23}$.

No study clearly described allocation concealment. Only six studies were blinded $d^{12,13,19,20,21,23}$, and only four studies described the blinding of the assessors $^{19,20,21,23}$. In addition, six studies reported losses and exclusions that occurred during the treatment period ${ }^{11,12,14,21,23,24}$. Two studies ${ }^{13,20}$ reported the analysis by intention to treat.

Therefore, the sensitivity analyses were hampered by a lack of methodological quality of the included studies and the small number of studies and participants.

A meta-analysis of all the articles included in this systematic review could not be performed due to the different types of electrical stimulation applied and the different methods used to assess pain and evaluate sensitivity. Moreover, three studies ${ }^{13,14,23}$ assessed the sensitivity of different techniques.

In the meta-analysis of TENS versus placebo, four studies $^{11-13,15}$ applied TENS to the lower limbs, and only one study applied it to the upper limbs 14 and demonstrated improvement in pain sensation. Despite the structural and functional differences of the upper and lower limbs, diabetic neuropathy manifests in the extremities ("boot" and "glove") due to the involvement of peripheral nerves, which explains the application of TENS in these regions. In one study ${ }^{12}$, 
it was found that treatment with amitriptyline for 20 weeks before the electrical stimulation may also affect the outcome.

However, in the meta-analysis of studies involving TENS versus placebo, the criteria for pain assessment were different. Two studies ${ }^{11,12}$ rated the level of pain and discomfort on a scale of 0 to 5 and included questions intended to provide a description of the symptoms, paresthesias, intensity and frequency of pain, sleep disturbance in relation to neuropathic pain and functional impairment, while three other studies $^{13-15}$ assessed pain using a visual analog scale from 0 (no pain) to 10 (unbearable pain). For the analysis of data, information relating to the scales of pain was normalized, and despite the different instruments used for the purpose of evaluation in the studies, there was no heterogeneity.

In the meta-analysis of electromagnetic stimulation versus placebo, there was no significant improvement in pain relief for patients who received electromagnetic stimulation. This can be explained by the methodological differences between the included studies in terms of the parameters of magnetic fields used (exposure profile). The devices used to generate the magnetic fields were different between studies, as one study assessed the exposure to a pulsed electromagnetic field ${ }^{18}$, another study assessed exposure to a static magnetic field ${ }^{20}$, and two studies assessed low-frequency pulsed magnetic exposure $^{19,21}$. Regarding exposure duration, one study performed less exposure ${ }^{21}$, and two studies had shorter total exposure times ${ }^{18,21}$. In addition, two studies had a small number of patients ${ }^{18,21}$.

In the sub-analysis of treatment duration, two articles ${ }^{12,13}$ evaluated pain after 12 weeks of treatment and found no significant improvement. This can be explained by the small number of studies included in the sub-analysis and the insufficiency of the sample size to demonstrate efficacy.

\section{Comparison with other studies}

Recently, Jin et al..$^{35}$ published a meta-analysis of randomized controlled studies with the objective of evaluating the effectiveness of TENS in peripheral diabetic neuropathy. This article included only three studies involving a total of 78 patients, and the authors concluded that TENS may be safe and effective in treating the symptoms of diabetic neuropathy. Although the above study answers one of our research questions, it differs from ours in that it does not include other types of electrical stimulation or electromagnetic stimulation and in the small number of studies included.

\section{Conclusions}

In conclusion, transcutaneous electric nerve stimulation therapy may be an effective and safe strategy for the treatment of symptomatic diabetic neuropathy. By contrast, there was no improvement with the use of electromagnetic fields. Due to the methodological differences between the included studies, it was not possible to perform a metaanalysis of the outcome of sensitivity. The limited number of studies involving electrical stimulation and electromagnetic stimulation, the different treatments studied, the different parameters used and the low quality of included studies demonstrate the need for further randomized clinical trials designed with greater methodological rigor to establish the true efficacy of these therapies in diabetic neuropathy.

\section{Acknowledgments}

The Coordenação de Aperfeiçoamento de Pessoal de Nivel Superior (CAPES), Brazil, Conselho Nacional de Desenvolvimento Científico e Tecnológico (CNPq), Brazil, and Fundação de Amparo a Pesquisa do Estado do Rio Grande do Sul (FAPERGS), Brazil.

\section{References}

1. Wild S, Roglic G, Green A, Sicree R, King H. Global prevalence of diabetes: estimates for the year 2000 and projections for 2030. Diabetes Care. 2004;27(5):1047-53. http://dx.doi.org/10.2337/diacare.27.5.1047

2. Boulton A, Ward J. Diabetic neuropathies and pain. Clin Endocrinol Metab. 1986;15(4):917-31. http://dx.doi. org/10.1016/S0300-595X(86)80080-9

3. Gregg EW, Sorlie P, Paulose-Ram R, Gu Q, Eberhardt MS, Wolz M, et al. Prevalence of lower-extremity disease in the U.S. adult population $>40$ years of age with and without diabetes. Diabetes Care. 2004;27(7):1591-97. PMid:15220233. http://dx.doi.org/10.2337/ diacare.27.7.1591

4. Poncelet AN. Diabetic polyneuropathy: risk factors, patterns of presentation, diagnosis, and treatment (Review). Geriatrics. 2003;58(6):16-8, 24-5, 30. PMid:12813869.

5. Benbow SJ, Wallymahmed ME, MacFarlane IA. Diabetic peripheral neuropathy and quality of life. QJ Med. 1998;91(11):733-37. http://dx.doi.org/10.1093/ qjmed/91.11.733

6. Davies M, Brophy S, Williams R, Taylor A. The prevalence, severity, and impact of painful diabetic peripheral neuropathy in type 2 diabetes. Diabetes Care. 2006;29(7):1518-22. PMid:16801572. http://dx.doi. org/10.2337/dc05-2228

7. Daousi C, MacFarlane IA, Woodward A, Nurmikko TJ, Bundred PE, Benbow SJ. Chronic painful peripheral 
neuropathy in an urban community: a controlled comparison of people with and without diabetes. Diabet Med. 2004;21(9):976-82. PMid:15317601. http://dx.doi. org/10.1111/j.1464-5491.2004.01271.x

8. Bril V, England J, Franklin GM, Backonja M, Cohen J, Del Toro D, et al. Evidence-based guideline: treatment of painful diabetic neuropathy. Neurology. 2011;76(20):1758. PMid:21482920 PMCid:3100130. http://dx.doi. org/10.1212/WNL.0b013e3182166ebe

9. Somers D, Somers M. Treatment of neuropathic pain in a patient with diabetic neuropathy using transcutaneous electrical nerve stimulation applied to the skin of the lumbar region. Phys Ther. 1999;79(8):767. PMid:10440663.

10. Larsen PR, Kronenberg HM, Melmed S, Polonsky KS. Williams textbook of endocrinology. 10th ed. Philadelphia: Saunders; 2003. p. 177-280.

11. Kumar D, Marshall H. Diabetic peripheral neuropathy: amelioration of pain with transcutaneous electrostimulation. Diabetes Care. 1997;20(11):1702. http://dx.doi.org/10.2337/diacare.20.11.1702

12. Kumar D, Alvaro M, Julka I, Marshall HJ. Diabetic peripheral neuropathy. Effectiveness of electrotherapy and amitriptyline for symptomatic relief. Diabetes Care. 1998;21(8):1322. http://dx.doi.org/10.2337/ diacare.21.8.1322

13. Forst T, Nguyen M, Forst S, Disselhoff B, Pohlmann T, Pfützner A. Impact of low frequency transcutaneous electrical nerve stimulation on symptomatic diabetic neuropathy using the new Salutaris ${ }^{\circledR}$ device. Diabetes Nutr Metab. 2004;17(3):163-8. PMid:15334794.

14. Cheing G, Luk M. Transcutaneous electrical nerve stimulation for neuropathic pain. J Hand Surg Br. 2005;30(1):50-5. PMid:15620492. http://dx.doi. org/10.1016/j.jhsb.2004.08.007

15. Gossrau G, Wähner M, Kuschke M, Konrad B, Reichmann $\mathrm{H}$, Wiedemann B, et al. The microcurrent transcutaneous electric nerve stimulation in painful diabetic neuropathy: a randomized placebo-controlled study. Pain Medicine. 2011;12(6):953-960. PMid:21627767. http:// dx.doi.org/10.1111/j.1526-4637.2011.01140.x

16. Musaev A, Guseinova S, Imamverdieva $S$. The use of pulsed electromagnetic fields with complex modulation in the treatment of patients with diabetic polyneuropathy. Neurosci Behav Physiol. 2003;33(8):745-52. http://dx.doi. org/10.1023/A:1025184912494

17. Weintraub M, Cole S. Pulsed magnetic field therapy in refractory neuropathic pain secondary to peripheral neuropathy: electrodiagnostic parameters-pilot study. Neurorehabil Neural Repair. 2004;18(1):42-6. PMid:15035963. http://dx.doi. org/10.1177/0888439003261024

18. Fezyoglu P, Özdemir F, Güldiken S, Balci K, Süt N. The effects of pulsed electromagnetic field treatment in pain due to diabetic polyneuropathy. Trakia Univ Tip Fak Derg. 2010;27(3):227-233.

19. Weintraub M, Herrmann D, Smith A, Backonja MM, Cole SP. Pulsed electromagnetic fields to reduce diabetic neuropathic pain and stimulate neuronal repair: a randomized controlled trial. Arch Phys Med
Rehabil. 2009;90(7):1102-9. PMid:19577022. http:// dx.doi.org/10.1016/j.apmr.2009.01.019

20. Weintraub M, Wolfe G, Barohn R, Cole SP, Parry GJ, Hayat G, et al. Static magnetic field therapy for symptomatic diabetic neuropathy: a randomized, double-blind, placebo-controlled trial. Arch Phys Med Rehabil. 2003;84(5):736-46. http://dx.doi.org/10.1016/ S0003-9993(03)00106-0

21. Wróbel M, Szymborska-Kajanek A, Wystrychowski G, Biniszkiewcz T, Sierón-Stollny K, Sierón A, et al. Impact of low frequency pulsed magnetic fields on pain intensity, quality of life and sleep disturbances in patients with painful diabetic polyneuropathy. Diabetes Metab. 2008;34(4 -Pt 1):349-54.

22. Reichstein L, Labrenz S, Ziegler D, Martin S. Effective treatment of symptomatic diabetic polyneuropathy by high-frequency external muscle stimulation. Diabetologia. 2005;48(5):824-8. PMid:15830180. http:// dx.doi.org/10.1007/s00125-005-1728-0

23. Bosi E, Conti M, Vermigli C, Cazzetta G, Peretti $\mathrm{E}$, Cordoni MC, et al. Effectiveness of frequencymodulated electromagnetic neural stimulation in the treatment of painful diabetic neuropathy. Diabetologia. 2005;48(5):817-23. PMid:15834546. http:// dx.doi.org/10.1007/s00125-005-1734-2

24. Hamza MA, White PF, Craig WF, Ghoname ES, Ahmed HE, Proctor TJ, et al. Percutaneous electrical nerve stimulation: a novel analgesic therapy for diabetic neuropathic pain. Diabetes Care. 2000;23(3):365. http:// dx.doi.org/10.2337/diacare.23.3.365

25. Higgins J, Green S. Cochrane handbook for systematic reviews of interventions. 5.0 ed. Chichester: John Wiley \& Sons; 2011.

26. Moher D, Liberati A, Tetzlaff J, Altman DG, Prisma Group. Reprint-Preferred Reporting Items for Systematic Reviews and Meta-Analyses: The PRISMA Statement. Phys Ther. 2009;89(9):873. PMid:19723669.

27. Robinson K, Dickersin K. Development of a highly sensitive search strategy for the retrieval of reports of controlled trials using PubMed. Int J Epidemiol. 2002;31(1):150. http://dx.doi.org/10.1093/ije/31.1.150

28. Higgins J, Thompson S, Deeks J, Altman DG. Measuring inconsistency in meta-analyses. BMJ. 2003;327(7414):327:557.

29. Sluka KA, Deacon M, Stibal A, Strissel S, Terpstra A. Spinal blockade of opioid receptors prevents the analgesia produced by TENS in arthritic rats. J Pharmacol Exp Ther. 1999;289(2):840-6. PMid:10215661.

30. Kalra A, Urban MO, Sluka KA. Blockade of opioid receptors in rostral ventral medulla prevents antihyperalgesia produced by transcutaneous electrical nerve stimulation (TENS). J Pharmacol Exp Ther. 2001;298(1):257-63. PMid:11408550.

31. Collins HL, DiCarlo SE. TENS attenuates response to colon distension in paraplegic and quadriplegic rats. Am J Physiol Heart Circ Physiol. 2002;283(4):1734-39.

32. Melzack R, Wall PD. Pain mechanisms: a new theory. Science. 1967;150(3699):971-79. http://dx.doi. org/10.1126/science.150.3699.971 
33. Chandran P, Sluka KA. Development of opioid tolerance with repeated transcutaneous electrical nerve stimulation administration. Pain. 2003;102(1-2):195-201. http:// dx.doi.org/10.1016/s0304-3959(02)00381-0

34. Hansson PT, Fields HL, Hill RG, Marchettini P. Neuropathic pain: pathophysiology and treatment. Settle: IASP Press; 2001. p. 63-124. PMid:11426927.

35. Jin D, Xu Y, Geng D, Yan T. Effect of transcutaneous electrical nerve stimulation on symptomatic diabetic peripheral neuropathy: a meta-analysis of randomized controlled trials. Diabetes Res Clin Pract. 2010;89(1):10-5. PMid:20510476. http://dx.doi.org/10.1016/j. diabres.2010.03.021

\section{Correspondence}

\section{Rodrigo Della Méa Plentz}

Universidade Federal de Ciências da Saúde de Porto Alegre Departamento de Fisioterapia

Rua Sarmento Leite, 245

CEP 90050-170, Porto Alegre, RS, Brasil

e-mail: roplentz@yahoo.com.br; rodrigop@ufcspa.edu.br 